\title{
AMÉRICA LATINA: ENTRE A AFIRMAÇÃO E A PERMANÊNCIA DA VIOLAÇÃO DE DIREITOS HUMANOS
}

\section{PAULO WEYL}

Paulo Weyl é coordenador do Programa de Pós-Graduação em Direito da Universidade Federal do Pará, Brasil.

psweyl@uol.com.br

Artigo submetido em português 
A história da América Latina, desde a última vintena do século XX, registrou importantes transformações na disposição dos direitos internos. Em geral, após a experiência de décadas de regimes ditatórias, com o predomínio da negação dos direitos políticos, avançamos no sentido das democracias constitucionais, com a consolidação de Estados organizados sobre uma base cidadã, de proteção aos direitos fundamentais e promoção dos direitos humanos. Tal estrutura jurídica implica a constituição de um sistema de direitos e instrumentos de proteção de cidadania e direitos humanos, destacando dentre eles os direitos políticos, permitindo aos povos experiências políticas singulares em sua história.

Exemplos dessas conquistas são a crescente incorporação dos conteúdos das declarações de direitos às ordens jurídicas internas, o fortalecimento e ampliação dos sistemas internacionais de proteção, o crescente reconhecimento dos mecanismos internacionais de proteção, que permite a articulação entre o sistema interno de proteção dos direitos fundamentais e o sistema internacional de proteção dos direitos humanos.

Esse movimento, todavia, não se dá sem conflitos. É um percurso sinuoso de idas e vindas e não se mostra homogêneo, não se realiza da mesma forma em todos os países latino-americanos. O estudo desses processos vivenciados em cada País evidencia os avanços alcançados e mostra também que, não obstante às conquistas obtidas, não logramos alterar a herança negativa dos direitos humanos em nossa região. Mais drástico, a convivência de realidades distintas, de transformações institucionais que as adéquam a modernos discursos e segundo valores que as fundamentam, com realidades sociais de fragilidade de direitos, evidenciam realidades complexas e o ensaio de realidades sóciohistóricas (modelos) que articulam desenvolvimento econômico com discurso de proteção de direitos e, paradoxalmente, miséria, exclusão social e a degradação humana.

Não se trata de uma inexorável direção. Mas é necessário um esforço compreensivo no sentido de identificar os elementos dessa realidade, visando a propor transformações em suas estruturas. Nessa direção, apontamos algumas circunstâncias comuns a nossas realidades.

a) A fragilidade do sistema de direitos: a forma da inserção dos países da América Latina no último ciclo de globalização e as estabilizações de suas economias, experimenta conflitos com a estrutura de direitos. A demanda por reformas jurídicas, por exemplo, acompanhando o consenso neo liberal, mostrou-se tendente a diminuir o papel do Estado, sem criação ou mantença de um sistema de proteção social e promoção do desenvolvimento.

Sob a hegemonia e o senso comum do custo do capital, estão distantes da promoção do desenvolvimento humano segundo o princípio da dignidade do trabalhador, da proteção e da defesa do valor do trabalho, mediante processos inclusivos, que implicaria o acesso aos bens humanos educação, cultura, saúde -, e a distribuição menos desigual da riqueza interna.

b) No que atine ao exercício dos direitos substantivos, vivenciamos sistemas onde predominam a baixa densidade dos direitos humanos.

A história da proteção judicial dos direitos humanos na América Latina é marcada por várias rupturas com o Estado de Direito. Na maioria dos países latino-americanos, foram reconhecidas garantias fundamentais como o habeas corpus e adotado o controle difuso de constitucionalidade das leis, além de um conjunto de procedimentos céleres para a tutela dos direitos humanos, conhecidos genericamente como "direito de amparo". No entanto, o longo período de autoritarismo implica obstáculos à consolidação dessas garantias.

A partir da década de 80 , o retorno aos regimes democráticos possibilitou uma nova onda de reconhecimento dos direitos humanos, na qual destacam-se como os fatos mais importantes: a) a adoção de novas Constituições, que ampliaram o catálogo dos direitos fundamentais e criaram 
novas garantias jurisdicionais; b) a incorporação dos tratados internacionais de direitos humanos ao ordenamento interno, dotando-os de hierarquia constitucional em alguns países; c) o reconhecimento da competência da Corte Interamericana de Direitos Humanos por vinte e um países da região.

Esses avanços, contudo, em geral foram contemporâneos á falência econômica dos modelos empregados pelas ditaduras políticas. Assim, as dissensões políticas foram também acompanhadas de reformas econômicas, sob a égide das reformas liberais, que implicaram no enfraquecimento do estado e de sua capacidade para sustentar a adoção de políticas públicas com alcance da garantia de direitos humanos.

Paradoxalmente, no processo inverso à garantia formal de direitos políticos e aos programas constitucionais de direitos econômicos, sociais e culturais, as décadas de 80 e 90 acentuaram a pobreza e a desigualdade. Essa combinação também conduziu ao aumento e a diversificação da violência. Assim, não obstante às importantes reformas de seus sistemas constitucionais, os países latino-americanos não conseguiram superar antigas formas de violação dos direitos humanos, tal como demonstram os conflitos agrários e a persistência do trabalho indigno, nem evitar a emergência de novas formas de violação, a exemplo dos danos provocados ao meio ambiente.

c) A permanência da violência estatal contra a cidadania. A violência do aparato estatal é uma forma especial e preocupante de resistência da adequação do aparato institucional ao regime de direitos fundamentais e de direitos humanos. Denota que o Estado não se abre inteiramente ao domínio da virtude da democracia e dos direitos.

Não atinge de igual a toda sociedade. Seus efeitos alcançam de forma drástica as populações das periferias e das favelas dos grandes centros urbanos, especialmente negros, homossexuais e as mulheres. Demonstra sua "eficiência" quando destinada a controlar movimentos sociais. Sob a justificativa do combate ao crime, os direitos civis das populações são solenemente violados, via da presunção da culpa e mesmo de julgamentos e execuções sumárias.

Outra face da violência institucional é a associação de integrantes da segurança pública ao tráfico, atuando abertamente como proteção do crime, ao que se combina a permissividade das políticas de segurança, que, incapazes de reprimir esse movimento, se abrem à perigosa contaminação institucional.

Por que o aparato de segurança atua contra a cidadania? Em alguns casos, qual a razão da permanência de grupos de extinção nos órgãos de segurança pública e da associação de seus integrantes com o crime organizado? As consequiências drásticas da forma perversa de relação dos órgãos de segurança ganham noticias nos casos de chacinas que se repetem nas áreas urbanas e rurais do Brasil e repercutem em dados cruéis, como o da expectativa de vida da população jovem, vitimados em razão dessa perversa combinação.

Nesse cenário, destacamos que o avanço dos sistemas de direito na América Latina, na direção de regimes constitucionais democráticos, segundo pautas normativas de direitos fundamentais e direitos humanos, desenvolve-se sob bases reais complexas, exigindo a articulação da cultura de direitos humanos em prol da ampliação e hegemonia de seus princípios constituintes. Nesse sentido, apresentamos o presente projeto, da formação de um Consórcio Latino-Americano de Pós-Graduação em Direitos Humanos. 


\section{A FORMAÇÃO DE DIREITOS, O SENSO COMUM TEÓRICO}

Esse contexto, marcado por conflitos entre as mudanças institucionais e violações reais de direitos humanos, demanda o fortalecimento da cultura de direitos e a criação de um novo senso comum teórico de direitos, favorável à realização material dos direitos humanos. Pensamos que um processo nessa direção deve observar particularidades históricas e culturais. Longe de uma postura regionalista, a observação da historia e da cultura pode evitar a mera e perigosa recepção dos discursos dominantes e, sem dúvida, facilitar o diálogo, com a legitimação de novos autores e de novos lugares da fala.

A realidade de direitos humanos estrutura-se sob a história de uma formação cultural própria dessa região. Tendo a experiência de nossa historia como norte, ressalvamos que os valores do humanismo que informam a cultura jurídica européia não se realizam plenamente nas instituições e nas políticas. Nossa herança liberal foi em muitos casos recepcionada por uma cultura ainda escravista e colonizadora, que subtraiu o valor libertário e civilizatório do direito sob aquela compreensão. Essa recepção particular do liberalismo subjacente ao direito acentua o caráter autoritário e heterogêneo da norma, sobrepondo seu caráter instrumental ao poder. Assim, em muitos casos de nossa história, o direito foi para justificar exemplos extremos, como a longa duração da escravidão, o genocídio de nações indígenas, bem como os regimes autocráticos. Esses são traços de uma herança de resistência a direitos, amparada em um discurso do direito, sempre articulado aos interesses econômicos do poder.

Com efeito, o que mostra o exemplo do Brasil, nossa história não vivenciou a fase dos direitos humanos como expressão de liberdade individual e limite positivo do poder, marca do pensamento liberal. Esse é um discurso do pensamento jurídico, mas que não vivenciamos como experiência. Nos trópicos, o liberalismo, não logrou, que estruturar a constituição do império, sustentar a escravidão e alimentar a guerra do Paraguai, por exemplo.

Essa é uma particularidade que não é refletida na cultura jurídica latino-americana, mas que tem forte influência em nossa pré-compreensão. Vivenciando a experiência liberal como um discurso externo e não como uma prática institucional, nossas instituições jurídico-políticas, nos momentos de sua afirmação social, tendem a responder desde as marcas que registram sua formação cultural.

Essa observação não tem a função de reclamar a necessidade da experiência do direito contemporâneo, segundo as bases do humanismo eurocêntrico. Na realidade, a base teórica do direito e do pensamento herdado é no mínimo crítica para sustentar uma reflexão profunda acerca dos direitos humanos. O pensamento jurídico hegemônico, com a constituição de uma ciência jurídica dogmática, articulado sobre conceitos duros, problemáticos, que, transformados em senso comum jurídico, implica um modelo categórico que não se ajusta sem problemas à efetividade dos direitos humanos. O fato, pois, é que nossa experiência e nossos recursos teóricos são instrumentos insuficientes para pensar o direito sobre a ótica da dignidade humana.

Nesse sentido, Hendu pretende-se um instrumento do pensamento latino-americano, para refletir o conceito e a fundamentação dos direitos humanos, com vistas a ampliar a compreensão dos processos humanos de produção e justificação da desigualdade e exclusão social. A construção dos diretos humanos, com efeito, requer a crítica constante sobre as fundações do pensamento que tornam possíveis e aceitáveis as formas políticas e econômicas que afastam o ser humano de sua dignidade.

A identificação dos direitos humanos com a luta contra a privação de direitos (formais e materiais) que aflige a maior parte da sociedade humana dá aos direitos humanos uma dimensão pragmática de relevantes desdobramentos. A relação imediata dos direitos humanos com uma pauta implica um importante ativismo político, que impulsiona conquistas normativas e veicula a inserção de 
parcelas da população a processos negociais, ampliando os espaços de racionalidade publica.

A luta por direitos, acima de tudo, implica a práxis no sentido de uma sociedade mais racional quanto possível, capaz de criar as condições de elevação do ser humano e de aproveitá-las em seu beneficio.

O ativismo, de certa maneira, condiciona a compreensão conceitual desses direitos, impondo uma idéia imediata e limitada da natureza dos direitos humanos. Mas a liberdade que se amplia nas formas democráticas, longe de conferir certezas acerca dos direitos humanos, evidência a amplitude e complexidade das formas desses direitos. As mudanças vivenciadas na América Latina mostram que os direitos humanos não se deixam aprisionar por pautas determinadas e definitivas, pois, se os direitos humanos eram identificados nas pautas por liberdade políticas, sob os regimes autoritários, nas democracias que os sucederam, se espraiam em pautas diversas, como contra a exclusão social e a violência - inclusive do Estado, como a violência policial, dentre outras.

Esse movimento denota a natureza dinâmica dos direitos humanos, que possuem uma relação complexa com a própria idéia de direito.

O diálogo é um instrumento rico e exerce função cognitiva de produção do conhecimento. O ensino dos direitos humanos implica a constante pesquisa desse aberto e dinâmico "objeto". Para além das pautas normativas - sem distar delas -, se impõe a necessidade de ampliar os processos compreensivos acerca do humano, de sua natureza, da sua cultura como uma dimensão de sua natureza, de suas normas como uma das dimensões de sua forma, de seu viver.

Em um sentido, a pesquisa dos direitos humanos se confunde com o retorno ao pensamento filosófico, com a demanda de pensar o pensamento. A começar por sua própria definição, ou rendição ante a radicalidade de sua abertura, que não o deixa apreender pelos mesmos conceitos e categorias instrumentais da forma de saber consagrada pela modernidade - a ciência.

A pesquisa dos direitos humanos requer refletir em torno das condições de possibilidades, reprodução e justificação das formas simbólicas, sociais e políticas permissivas, que tornam banal a violação do meio ambiente, vulgarizam violações diversas e naturalizam relações humanas de submissão, exclusão, exploração e discriminação.

Sob essa crítica, a ciência demanda uma compreensão diversa do sujeito e do conhecimento. Tratase de perceber as variadas formas de apreensão do real, o que implica uma abertura metodológica que permita mesmo a reconstrução e preservação de saberes, hoje marginalizados pelo exclusivismo científico - como é o caso dos saberes seculares que se perdem com a extinção de culturas indígenas, por exemplo.

Conquista humana da maior magnitude, as ciências constituem um conjunto simbólico de conceitos que denotam o mundo em outras cores. Mas, se potencializam a capacidade produtiva, alimentam os horizontes e a fé no futuro humano, igualmente ampliam o potencial destrutivo do homem e da natureza. A sociedade humana não as apropria para a erradicação das mazelas humanas, como a fome e as doenças endêmicas, ou para um desenvolvimento econômico de produção de riqueza compatível com a natureza e a garantia do direito das futuras gerações a um meio ambiente equilibrado.

No âmbito da teoria do direito, a pesquisa dos direitos humanos impõe indagar a relação existente entre o sistema doutrinário e normativo de que se compõe e as realidades sociais excludentes. Torna-se necessário indagar se o direito é condição de liberdade humana, se é pressuposto da realidade de exclusão, ou mesmo se é de sua natureza a ambigüidade que permite ambas realidades. 
No mesmo sentido disjuntivo, da separação homem e natureza, edificante da ciência moderna, convém refletir o alcance da hipótese constitutiva da modernidade, da precedência do homem à sociedade como hipótese marcante a um só tempo, da dignidade humana, mas criadora de uma importante tensão e mesmo oposição entre o indivíduo e a sociedade.

Vale destacar que, na larga difusão do instinto liberal, essa oposição implicou uma supremacia absoluta dos direitos individuais. Com a sucessão das eras de direitos, estaríamos distantes da realidade do liberalismo mais radical, não fosse a força dessa cultura e a disseminação de seus conceitos, ainda hoje fortemente presente no senso comum jurídico. Melhor, na formação de juízes, promotores, advogados, professores e alunos de direito.

\section{A INTELIGÊNCIA DAS NOVAS CONFIGURAÇÕES NORMATIVAS}

A consideração dos direitos humanos tem à frente o desafio da inteligência da complexidade do desenvolvimento dos direitos na América Latina, uma dinâmica marcada pela tensão frente ao duplo movimento de direitos: de um lado a pressão exercida pela globalização econômica pela supressão de direitos, de outro, o movimento histórico de positivação dos direitos humanos, combinado com o fortalecimento de sistemas internacionais de proteção.

Considerando o largo domínio do positivismo jurídico, o direito absorve as novas realidades políticas e sociais com conceitos, no mínimo, problemáticos.

Sob esse prisma, sobressai a dificuldade de compreensão do impacto da globalização econômica sobre os processos de reforma dos sistemas jurídicos internos, sobretudo aqueles destinadas a suprimir direitos sociais. Nessa complexa realidade, a compreensão do direito demanda categorias de outras disciplinas, sob pena de limitar-se a um instrumento da técnica.

Para além da vaga - e forte - idéia da modernização das relações sociais, visando ajustar as normas internas às exigências do desenvolvimento econômico, vivencia-se um problema ético. A identificação da natureza do desenvolvimento que pretende a sociedade é a questão da qual a sociedade não pode se afastar. Um problema matricial para toda ordem de direitos.

Por outro lado, sobressai o movimento de positivação de direitos humanos. Sobre a base comum do princípio da dignidade da pessoa humana, os direitos fundamentais e os direitos humanos tendem a uma proximidade cada vez maior, o que é reforçado pelo conteúdo comum das declarações de direitos das Constituições contemporâneas e dos tratados de direitos humanos, crescentemente incorporados à ordem jurídica interna.

Assim, os instrumentos processuais de proteção dos direitos fundamentais passam a ser utilizados para a tutela dos direitos humanos, que tecnicamente vinculam a jurisdição nacional, mas que na prática exercem uma tensão importante, alvo de reflexões e estudos.

Além disso, o reconhecimento dos mecanismos internacionais de proteção permite uma articulação entre o sistema interno de proteção dos direitos fundamentais e o sistema internacional de proteção dos direitos humanos, considerando o caráter subsidiário da competência contenciosa da Corte Interamericana de Direitos Humanos e do Tribunal Europeu de Direitos Humanos. 


\section{CONCLUSÃO: AFIRMAÇÃO DOS DIREITOS HUMANOS COMO REFERÊNCIA HERMENÊUTICA}

À guisa da apresentação, entretanto, queremos ressalvar a ocorrência de fenômenos que se mostram comuns e aparentemente articulam as ordem jurídicas internas e, por essa razão, apóiam a ampliação de um diálogo dessas experiências.

Nesse sentido, destacamos a aparente ampliação do consenso em torno da idéia dos direitos humanos como valor estruturante e referencial do direito. Um fenômeno de certa forma recente e que, seguramente, não pode ser tratado como hegemônico no processo de decisão jurídico. Trata-se de um fenômeno significante, no sentido próprio da expressão. Os direitos humanos afirmam-se como uma dicção forte, com potência de criação de sentido. Nessa direção, em um processo que se assemelha ao valor da idéia da razão ao racionalismo, por exemplo, a hermenêutica jurídica contemporânea tem ampliado o recurso a esse poder de criação de sentido dos direitos humanos como estratégia da aplicação do direito.

Refere um processo tão complexo quanto precário. Rico porque fortalece a sociedade civil e dinamiza a compreensão do direito. A afirmação do valor significante dos direitos humanos, com efeito, enfraquece o monopólio da ciência jurídica, e dos juristas, sobre o discurso jurídico e o sentido do direito. $\mathrm{O}$ entendimento dos direitos humanos não encontra na tecnologia jurídica seu meio de acesso por excelência. Ao contrário, somos levados a perceber que a literatura jurídica convencional, em certos casos, pautada por regras formais, consiste em óbices para o acesso a esses direitos. Esse processo abre espaço ao fortalecimento dos atores da sociedade civil, em um processo que os legitima como interlocutores e fortalece a própria sociedade civil como locus privilegiado da criação do direito.

Esse processo implica uma crítica profunda à tradição do direito, que se afastou historicamente dos compromissos com os conteúdos valorativos estruturantes da sociedade política, em razão da afirmação da ciência, ao modelo da revolução científica, livre de todos os subjetivismos. Mas é, também, em um sentido positivo, um movimento delicado, pois, a medida que ocupa o lugar de um dogma, a fé cega da razão moderna, os direitos humanos sofrem um impacto no sentido da clausura, do fechamento de sentido.

\section{O CONSÓRCIO LATINO AMERICANO DE PÓS-GRADUAÇÃO EM DIREITOS HUMANOS}

As linhas acima informam de maneira muito resumida algumas das reflexões que conduziram a formação do Consórcio Latino Americano de Pós-Gradação em Direitos Humanos, que agora, com muita alegria, apresenta a Revista Hendu à comunidade acadêmica e política, aos defensores dos direitos humanos, aos movimentos sociais, aos artistas, aos índios, homens, mulheres, a essa imensa região, como um instrumento da construção de um novo topos.

Essas idéias constituíam o projeto redigido em 2005 por pesquisadores do Programa de PósGraduação em Direitos da Universidade Federal do Pará, que logo contou com o apoio entusiasta da Fundação Ford. A partir de 2005, essas idéias apoiaram o diálogo de vários pesquisadores, em uma série de encontros acadêmicos.

Em 2007, com o apoio econômico da Fundação Ford, foi realizado o Seminário Internacional, que culminou com a criação do Consórcio. Naquele encontro aderiram à criação da nova instituição, como fundadores, a Universidade Católica do Peru, a Universidade Iberoamericana do México, Universidade de Buenos Aires, Universidade de La Plata, Universidade Diego Portales, do Chile, a 
Universidade Externado da Colombia e, do Brasil, a Universidade Federal da Paraíba, Universidade de Brasília, além da Universidade Federal do Pará.

Após a fundação, aderiram à Iniciativa, a Universidade Austral do Chile e a Universidade do Vale do Rio dos Sinos, as quais participaram do $2^{\circ}$ Seminário do Consórcio realizado também em Belém, em novembro de 2008.

Por fim, o terceiro seminário do Consórcio, realizado em junho de 2009, em Lima, no Peru. Esses três eventos registraram uma serie de conquistas institucionais, dentre as quais a criação dos marcos metodológicos de um programa comum de ensino e investigação, que estrutura os marcos dos seminários a serem realizados e, também, a criação de Hendu, que ora vem a público.

O consórcio latino-americano de pós-graduação em direitos humanos visava, pois aproximar o diálogo entre experiências da investigação acerca da atualidade e da efetivação dos direitos humanos na América Latina. Com isso, fortalecer a cultura dos direitos nos países da região, visando ao aperfeiçoamento de seus mecanismos de proteção e promoção, a replicar as experiências inovadoras, a troca de experiências, ao desenvolvimento de investigações comuns, enfim, a criar um espaço regional do diálogo.

O Consórcio contribuirá para a formação de um pensamento latino-americano de direitos humanos, por meio de um esforço de compreensão da condição histórica da América Latina, de suas identidades e diferenças, visando ao desenvolvimento de conceitos e de configurações normativas próprias a essa condição.

O Consórcio, como agora HENDU, realiza a troca de experiências, de saberes, de conhecimentos que contribua à formação de um pensamento latino-americano de direitos humanos, por meio de um esforço de compreensão da condição histórica da América Latina, de suas identidades e diferenças, visando o desenvolvimento de conceitos e de configurações normativas próprias a essa condição. 